\title{
ULTRASONIC-ASSISTED EXTRACTION USING A BETAINE-BASED NATURAL DEEP EUTECTIC SOLVENT FOR RESVERATROL EXTRACTION FROM MELINJO (GNETUM GNEMON) SEEDS
}

\author{
WIDYA DWI ARYATI, KHUSNA MILLATI AZKA, ABDUL MUN'IM* \\ Department of Pharmacognosy and Phytochemistry, Faculty of Pharmacy, Universitas Indonesia, Depok, 16424, Indonesia. \\ Email: munim@farmasi.ui.ac.id
}

Received: 26 September 2019, Revised and Accepted: 24 December 2019

\begin{abstract}
Objective: Melinjo (Gnetum gnemon L.) seeds are known to contain resveratrol, which are classified as a phenolic compound of the stilbenoid. Melinjo seeds have high water content, making them unstable to be stored for prolonged periods with open packaging at room temperature. The present study aimed to explore the use of ultrasonic-assisted extraction with a betaine-based natural deep eutectic solvent (NADES) for resveratrol extraction from irradiated melinjo seeds.
\end{abstract}

Methods: The best betaine-based NADES component was identified among betaine-urea, betaine-lactic acid, and betaine-malic acid. Optimization of extraction methods was performed using the best NADES and extraction variables such as time of extraction, water percentage, and sample: solvent ratio. The outcome of extraction was evaluated by measuring resveratrol content using high-performance liquid chromatography and the results were analyzed using response surface methodology.

Results: The best betaine-based NADES was found to be betaine-lactic acid, yielding a resveratrol content of $0.3344 \mathrm{mg} / \mathrm{g}$ powder. The optimum extraction was achieved in $10 \mathrm{~min}$ with $60 \%$ water and a sample: solvent ratio of 1:10, yielding a resveratrol content of $0.227 \mathrm{mg} / \mathrm{g}$ powder.

Conclusion: Betaine-based NADES can be purposed as an alternative solvent for resveratrol extraction from irradiated melinjo seeds.

Keywords: Gnetum gnemon, Resveratrol, Natural deep eutectic solvent, Response surface methodology.

(C) 2020 The Authors. Published by Innovare Academic Sciences Pvt Ltd. This is an open access article under the CC BY license (http://creativecommons. org/licenses/by/4. 0/) DOI: http://dx.doi.org/10.22159/ijap.2020.v12s1.FF001

\section{INTRODUCTION}

Melinjo (Gnetum gnemon L.) is an open-seeded plant (Gymnospermae) of the Gnetaceae family [1]. It has a wide distribution and is easy to find in many areas. In addition, melinjo also has the ability to adapt to a range of environments and regenerate well [2]. Melinjo plants are referred to as multipurpose plants because almost all parts of the plant can be utilized [3]. Melinjo seeds contain resveratrol, which are classified as a stilbenoid phenolic compound [4]. Resveratrol has several pharmacological activities that are beneficial for health such as antioxidant activity, inhibition of platelet aggregation, antiinflammatory activity, and cancer prevention and inhibition activity [5]. Further, melinjo can be used as raw material for consumable herbal products, which can provide many health benefits [6]. The quality of melinjo plants to be used as raw material for herbal products is an important consideration, because it can affect the quality of the products. Elimination of contaminants is one of the critical parameters in achieving good product quality. Thus, reducing contamination of melinjo is essential to ensure quality of such herbal products; one useful method in this regard is irradiation [6]. Gamma-ray irradiation can trigger chemical or physiological changes that affect the water content of the extract [7].

Selection of the resveratrol extraction method is very important to obtain optimum compound content. Therefore, modern extraction methods such as ultrasonic-assisted extraction (UAE) are used due to their efficiency in terms of time and amount of solvent used, minimizing cost [8]. The use of organic solvents in the extraction process is not always environmentally friendly or safe for human health. Extraction methods using natural solvents that are environmentally friendly are now being developed; one such method is natural deep eutectic solvent (NADES) extraction [9]. NADES is a mixture of two or more components of natural origin at a particular molar ratio, which leads to strong depression of the melting point, often becoming liquids at room temperature [10]. NADES preparations can be combined with natural or commonly available ingredients such as sugar, alcohol, organic acids, and amino acids, leading to lower production costs and increased safety [11]. One such example is betaine-based NADES containing a mixture of several components (sugar, alcohol, organic acids, and urea); this solvent has been successfully used in a previous study to extract phenolic compounds from Chinese herbal medicines, namely, Salviae Miltiorrhizae Radix. In this extraction, the use of basic NADES with a mixture of organic acid and urea components resulted in a higher content of phenolic compounds than sugar and alcohol [12]. Sample extraction is affected by several factors resulting in variation in process and outcomes; therefore, an appropriate method is needed to optimize the extraction. Such optimization of extraction can be done using response surface methodology (RSM), a combination of mathematics and statistics, to produce a suitable and implementable unit process [13].

Studies on the use of NADES as a solvent for extraction to obtain optimum resveratrol content are limited. The present study performed resveratrol extraction from irradiated melinjo seeds with betaine-based NADES solvents containing several types of component mixtures using the UAE method, to identify the best betaine-based NADES component using RSM.

\section{MATERIALS AND METHODS}

Materials

Melinjo seeds (G. gnemon L.) were purchased from the local market in Serang, Banten. Betaine (Shandong, China), urea (Brataco, Indonesia), lactic acid (Brataco, Indonesia), malic acid (Brataco, Indonesia), demineralized aqua (Brataco, Indonesia), aqua pro injection (Brataco, Indonesia), methanol analytical grade (Merck, Germany), methanol 
high-performance liquid chromatography (HPLC) grade (Merck, Germany), acetonitrile HPLC grade (Merck, Germany), and resveratrol standard (Wako, Japan) were used in the present study.

\section{Preparation of materials}

Melinjo seeds with dry brown skin were sorted to remove extraneous material. The seeds were dried in a drying cabinet followed by dry sorting to separate remaining contaminants. Seeds weighing $0.5 \mathrm{~kg}$ were placed in a plastic container, which were tightly closed to be irradiated at a dose of $5 \mathrm{kGy}$. The irradiation source used was cobalt $60\left({ }^{60} \mathrm{Co}\right)$. The irradiation process was carried out at the Pusat Aplikasi Teknologi Isotop dan Radiasi, Pasar Jumat, South Jakarta. After the melinjo seeds were irradiated, they were ground until a fine powder was obtained.

\section{Preparation of NADES}

The NADES solvent used was a betaine base with combinations of four components; betaine: urea $(1: 1)[9,12,14]$, betaine: lactic acid $(1: 1)$ [12,15], and betaine: malic acid $(1: 1)$ [9,12]. There are three methods of preparation of NADES solvents, comprising heating and stirring methods, evaporation methods, and freeze-drying methods [16]. We used the heating method. First, betaine and its component mixtures were weighed. Second, the mixtures were stirred on a hotplate stirrer at $90^{\circ} \mathrm{C}$ and $500 \mathrm{rpm}$ for $90 \mathrm{~min}$. Third, water was added to dissolve the betaine in the mixture and the mixture was stirred again on the hotplate stirrer. Stable NADES was characterized by the formation of clear solutions. Finally, the solutions were stored in tightly closed vials.

\section{Extraction}

Melinjo seed extraction was performed using the UAE method. Melinjo seed powder $(0.5 \mathrm{~g})$ was dissolved with NADES at a different sample: solvent ratios. The sample solutions were extracted with an ultrasound apparatus and centrifuged at $4500 \mathrm{rpm}$ for $17 \mathrm{~min} \mathrm{[12].}$ The obtained liquid extract was then filtered using filter paper and the volume was adjusted using water in a flask of suitable volume.

\section{Identification of the best betaine-based NADES component}

Screening to identify the best betaine NADES component was done using HPLC. Extracts made using different NADES preparations (betaine-urea, betaine-lactic acid, and betaine-malic acid) were injected into an HPLC. The area under the curve values of the chromatograms were plotted using linear regression to obtain the resveratrol content of each test sample. The sample with the highest resveratrol level was then used for determination of the optimum extraction conditions. A Shimadzu LC-20AT HPLC was used at a wavelength of $306 \mathrm{~nm}$. The flow rate was $1.0 \mathrm{~mL} / \mathrm{min}$ and the injected volume was $20 \mu \mathrm{L}$. The mobile phase solvent used was aqua pro injection:acetonitrile $(75: 25 \mathrm{v} / \mathrm{v})$ at $\mathrm{pH} 3$, regulated with the addition of $0.01 \%$ acetic acid. The detector used was a ultraviolet-visible detector and the column used was Inertsil $150 \mathrm{~mm}$ $\times 4.6 \mathrm{~mm} ; 5$ m [17].

\section{Optimization of extraction conditions}

The experimental design for optimization of the extraction conditions was determined using RSM with Design Expert version 10.0 software and Box-Behnken as study design. The determination of optimal UAE was obtained by assessing resveratrol content from all samples. Data were entered into the software, which provided recommendations regarding the appropriate mathematical models. The recommended model was selected and further analyzed using ANOVA to determine the impact of each variable. The optimum level of each variable factor was determined on the basis of the desirability index, which has a value of $0-1$. A desirability index value approaching one indicates that the study design is closer to the optimum condition. The optimum condition was demonstrated using a three-dimensional surface response graph.

\section{The effect of temperature extraction on resveratrol level}

The test was performed by extracting samples at optimum extraction conditions at different temperatures. The first sample was extracted using an ultrasonicator without heating, whereas the second sample was extracted using an ultrasonicator with heating. The extracts obtained from both samples were then analyzed using HPLC and the resveratrol content of each sample was calculated. The resveratrol level was then compared to determine the effect of the extraction temperature.

\section{Comparison of the optimized method with the conventional} extraction method

The results of the optimized extraction conditions were compared with other extraction methods to verify whether the optimized method was more effective in extracting resveratrol from irradiated melinjo seeds. The resveratrol level obtained through the RSM method yielding the highest content was compared with that obtained through extraction using other conventional extraction methods such as maceration and reflux.

\section{RESULTS}

\section{Screening of the best betaine-based NADES components}

The betaine-lactic acid NADES solvent was found to be the best NADES component, yielding a resveratrol content of $0.3344 \mathrm{mg} / \mathrm{g}$ powder (Fig. 1).

\section{Optimization of extraction conditions}

The best extraction condition based on the results of data processing using Design Expert 10.0 Box-Behnken design was run 6, which used 10 min of extraction time, $60 \%$ water, and a sample: solvent ratio of $1: 10$, yielding a resveratrol content of $0.227 \mathrm{mg} / \mathrm{g}$ powder (Table 1 ).

\section{Effect of temperature}

Tests on samples extracted without heating resulted in an average resveratrol level of $0.111 \mathrm{mg} / \mathrm{g}$ powder. On the other hand, samples extracted by heating resulted in average resveratrol level of $0.153 \mathrm{mg} / \mathrm{g}$ powder (Fig. 2).

Comparison of extraction results with conventional extraction methods

Tests on sample run 6 resulted in average resveratrol content of $0.227 \mathrm{mg} / \mathrm{g}$ powder. The maceration sample yielded an average resveratrol content of $0.026 \mathrm{mg} / \mathrm{g}$ powder (Fig. 3).

\section{DISCUSSION}

\section{Identification of the best betaine-based NADES components}

Screening of betaine-based NADES components was done to select the NADES component yielding the highest resveratrol content. The comparison of each NADES used for extraction is shown in Fig. 1.

The results showed that betaine-lactic acid as an NADES component can extract phenolic compounds more effectively than betaine-urea and betaine-malic acid. The synthesis of NADES is easier and more stable without precipitation when the hydrogen bond donor is in a liquid form such as lactic acid. The interaction between betaine and

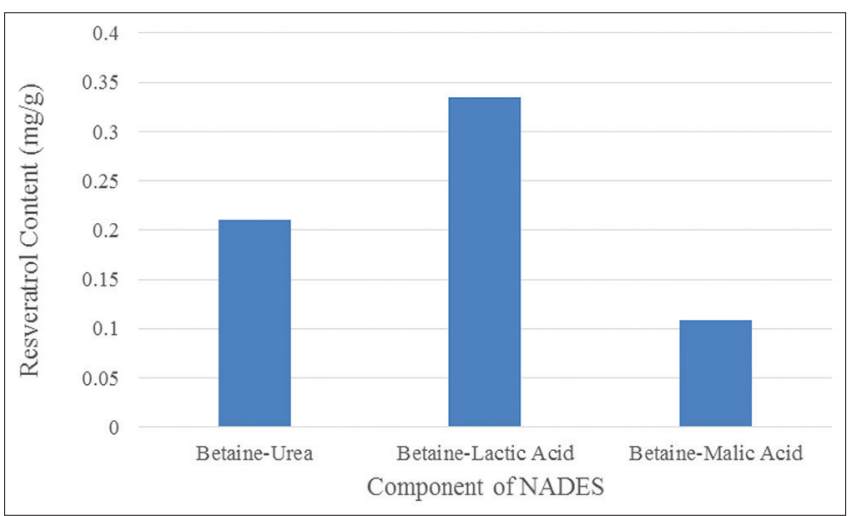

Fig. 1: Screening of betaine-based natural deep eutectic solvent components 
Table 1: Experimental design results using RSM (Box-Behnken design)

\begin{tabular}{|c|c|c|c|c|}
\hline Run & $\begin{array}{l}\text { Factor } 1 \text { (A) } \\
\text { Extraction time (min) }\end{array}$ & $\begin{array}{l}\text { Factor } 2(\mathrm{~B}) \\
\text { Water percentage (\%) }\end{array}$ & $\begin{array}{l}\text { Factor } 3(\mathrm{C}) \\
\text { Sample: Solvent ratio }(\mathrm{g} / \mathrm{mL})\end{array}$ & $\begin{array}{l}\text { Response: } \\
\text { Resveratrol content (mg/g) }\end{array}$ \\
\hline 1. & 10 & 50 & 20 & 0.182 \\
\hline 2. & 15 & 60 & 20 & 0.217 \\
\hline 3. & 5 & 50 & 10 & 0.171 \\
\hline 4. & 15 & 50 & 30 & 0.135 \\
\hline 5. & 10 & 40 & 10 & 0.184 \\
\hline 6. & 10 & 60 & 10 & 0.227 \\
\hline 8. & 5 & 40 & 20 & 0.142 \\
\hline 9. & 15 & 40 & 20 & 0.184 \\
\hline 10. & 10 & 50 & 20 & 0.187 \\
\hline 11. & 15 & 50 & 10 & 0.192 \\
\hline 12. & 10 & 50 & 20 & 0.171 \\
\hline 13. & 5 & 50 & 30 & 0.126 \\
\hline 14. & 10 & 40 & 30 & 0.104 \\
\hline 15. & 10 & 60 & 30 & 0.173 \\
\hline
\end{tabular}

RSM: Response surface methodology

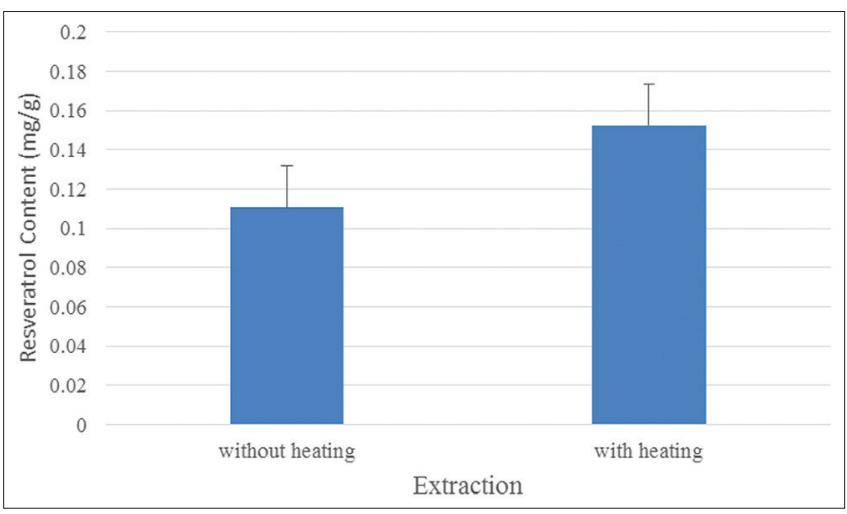

Fig. 2: Effect of temperature on resveratrol extraction levels

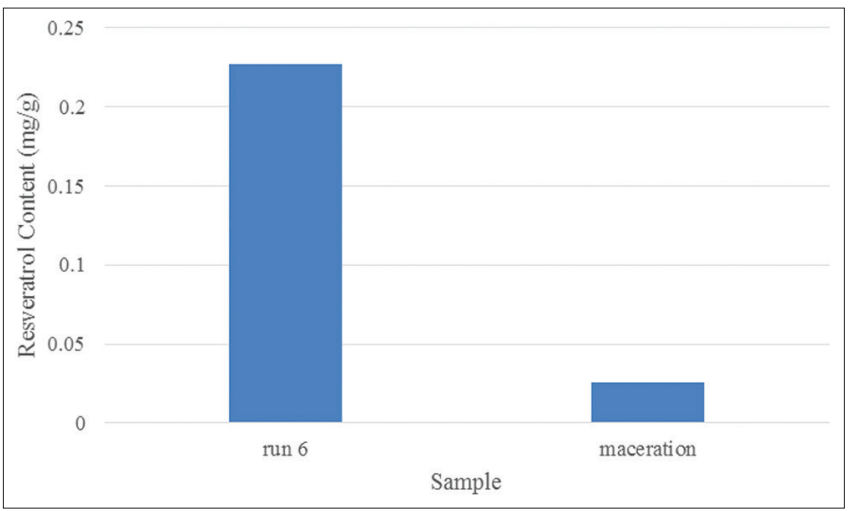

Fig. 3: Comparison of resveratrol level in run 6 with that in conventional extraction

resveratrol cannot be explained on the basis of the findings of the present study, and there are no supporting studies reporting such an interaction. Further, specific analysis such as molecular simulation analysis using heteronuclear Overhauser spectroscopy or nuclear Overhauser spectroscopy is needed [5]. However, NADES has a significant ability to extract phenolic compounds, which is associated through the hydrogen-bonding interactions formed between phenolic compounds and NADES molecules [15]. Resveratrol is also a phenolic compound, and it is predicted that reactions occurring between NADES and resveratrol are also associated with hydrogen-bonding interactions.

\section{Optimization of extraction conditions}

Determination of the optimum extraction conditions using the UAE method was done on the basis of resveratrol yield data shown in Table 1.

On the basis of the results of data processing using Design-Expert software, a recommended research model was obtained. The recommended research model was Quadratic versus $2 \mathrm{FI}$. This model was being recommended because it has a value of 0.0252 . The "prob $>F$ " $<0.05$ indicates significant influence, whereas a value $>0.05$ indicates an insignificant effect [18]. In addition, this research model has an insignificant "lack of fit" value of 0.4360 .

The research model recommendation was then analyzed using ANOVA with the aim to assess the significance of the model. In addition, it was also used to determine the probability of interaction between the research model and its variables. The ANOVA results showed that the value of "prob $>F$ " obtained from the recommended research model was 0.0020 . This indicated that the extraction conditions had a significant influence on resveratrol yield. The "prob $>F$ " values of the three factors extraction time, water percentage, and sample: solvent ratio also had a significant effect on the resveratrol yield. The "prob $>F$ " of extraction time was 0.0188 that of water percentage was 0.0006 and that of sample: solvent ratio was 0.0003 . A precise extraction time was required to ensure optimal extraction. The longer the extraction time, the better the extraction of polyphenol produced. Water addition to the NADES eutectic solution can reduce the viscosity of NADES. However, a high amount of water can also result in interactions between NADES and target compounds and improve polarity of extraction media; thus, water percentage can affect resveratrol yield. The sample: solvent ratio has been studied previously to improve extraction efficiency and reduce solvent usage. A high sample: solvent ratio did not show any significant improvement compared with a smaller sample: solvent ratio [15].

The RSM equation obtained for optimization of extraction conditions for resveratrol yield was as follows: Resveratrol

$$
\begin{gathered}
(y)=-5.125 \times 10^{-3} \mathrm{~A}^{2}+0.011 \mathrm{~B}^{2}-0.019 \mathrm{C}^{2}-6.250 \times 10^{-3} \mathrm{AB}-3.000 \times 10^{-3} \\
\mathrm{AC}+6.500 \times 10^{-3} \mathrm{BC}+0.011 \mathrm{~A}+0.025 \mathrm{~B}-0.030 \mathrm{C}+0.18
\end{gathered}
$$

\section{$A=$ Extraction time \\ $\mathrm{B}=$ Water percentage \\ $\mathrm{C}=$ Sample: solvent ratio}

The equation shows that the resveratrol yield increases with an increase in extraction time, water percentage, and interaction between water percentage and sample: solvent ratio. This is indicated by a positive constant value in the RSM equation obtained. The resveratrol level decreases with an increasing sample: solvent ratio, interaction between 


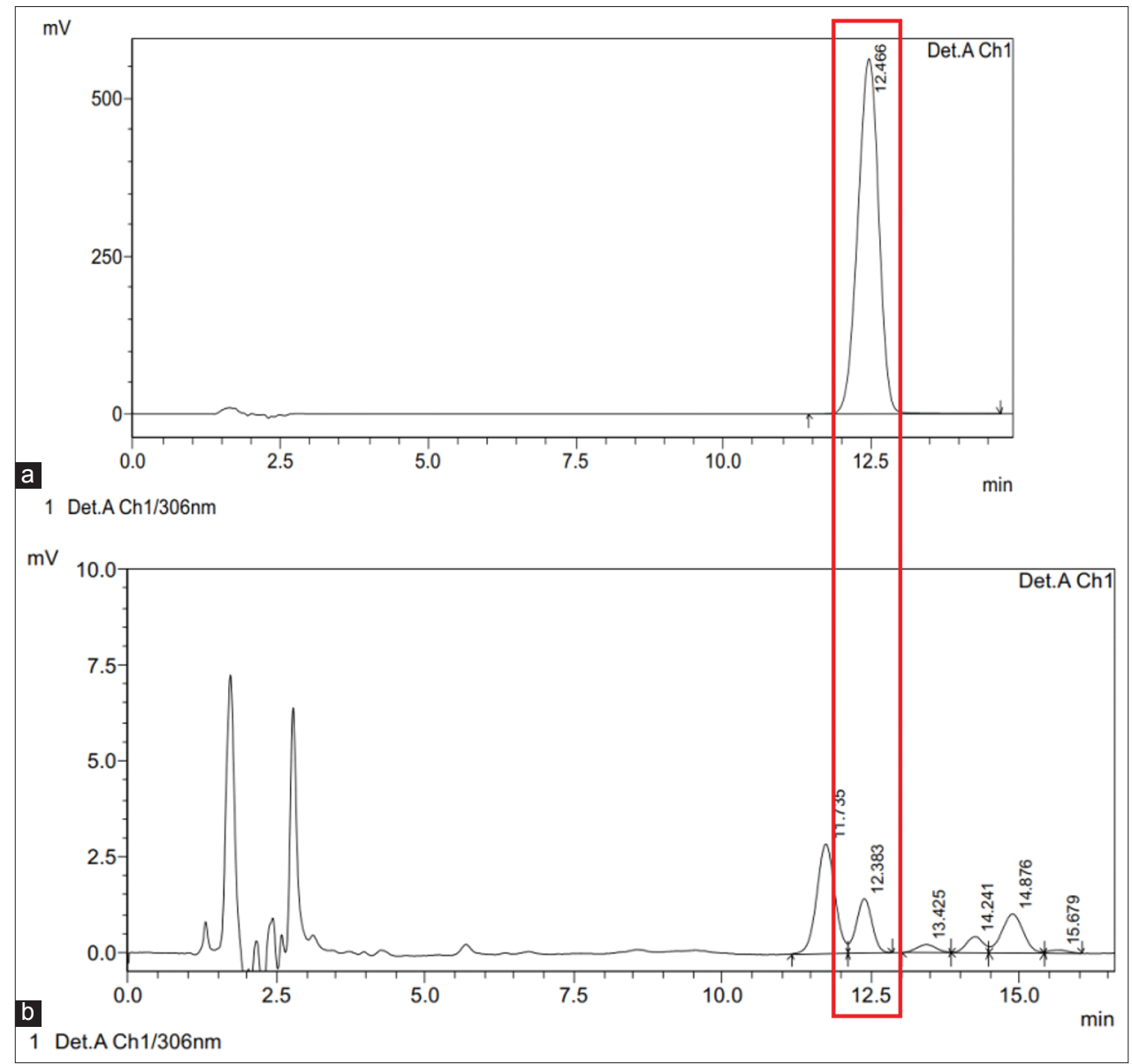

Fig. 4: High-performance liquid chromatography profile of resveratrol standard 100 ppm (a) and sample run 6 (b)

Table 2: Optimization of research models

\begin{tabular}{llll}
\hline Name & Goal & Lower limit & Upper limit \\
\hline Extraction time & In range & 5 & 15 \\
Water percentage & In range & 40 & 60 \\
Sample: solvent ratio & In range & 10 & 30 \\
Resveratrol level & Maximize & 0.104 & 0.227 \\
\hline
\end{tabular}

extraction time and water addition percentage, and interaction between extraction time and sample: solvent ratio. This is indicated by a negative constant value in the RSM equation obtained.

On the basis of the results of ANOVA, an optimum experimental factor was obtained. This optimum point was determined on the basis of the desirability index with a value between 0 and 1 . Therefore, the desirability index indicates the optimum conditions. The optimized research model is shown in Table 2 .

In the optimization of the research method, resveratrol yield was used as the criterion to determine the best extraction conditions. On the basis of the research model, 23 kinds of optimum extraction conditions were recommended and can be seen in Table 3 .

The research models obtained had the highest desirability index of 0.988 and the lowest desirability index of 0.746 . The model with desirability index 0.988 (run 6) was compared with resveratrol standard, and the chromatogram profile is shown in Fig. 4.

The surface response graph can be presented in three-dimensional form with different color gradations. However, the three-dimensional graphs produced in the present study were not optimal because the optimum point of the response of resveratrol level obtained did not lie in the curvature of the graph after the increase in response and before the decrease in response. The graphs are shown in Fig. 5.

\section{Effect of temperature on resveratrol extraction}

The effect of temperature on the optimum extraction conditions using RSM was then assessed. This was done by comparing two samples extracted using optimum RSM conditions, with one extracted using UAE with heating and the other one using UAE without heating. The extraction levels were then evaluated using HPLC and calculated by entering the area under the curve value obtained from the chromatograms into the existing regression equation. Each sample was tested three times and the result is shown in Fig. 2.

The level of resveratrol extracted at higher temperature was different compared with that at lower temperature. Increasing the extraction temperature can increase desorption and dissolution of secondary metabolites into the extraction solvents [15]. Thus, it can be concluded that the extraction temperature had an effect on the level of resveratrol extracted.

\section{Comparison with conventional extraction methods}

Extraction from irradiated melinjo seeds using NADES lactic acid with the optimum extraction method (run 6) yielded a higher resveratrol content compared with conventional maceration extraction methods using 70\% ethanol. The result is shown in Fig. 3.

On the basis of these results, the use of NADES for resveratrol extraction from melinjo seeds was better than the use of conventional maceration 


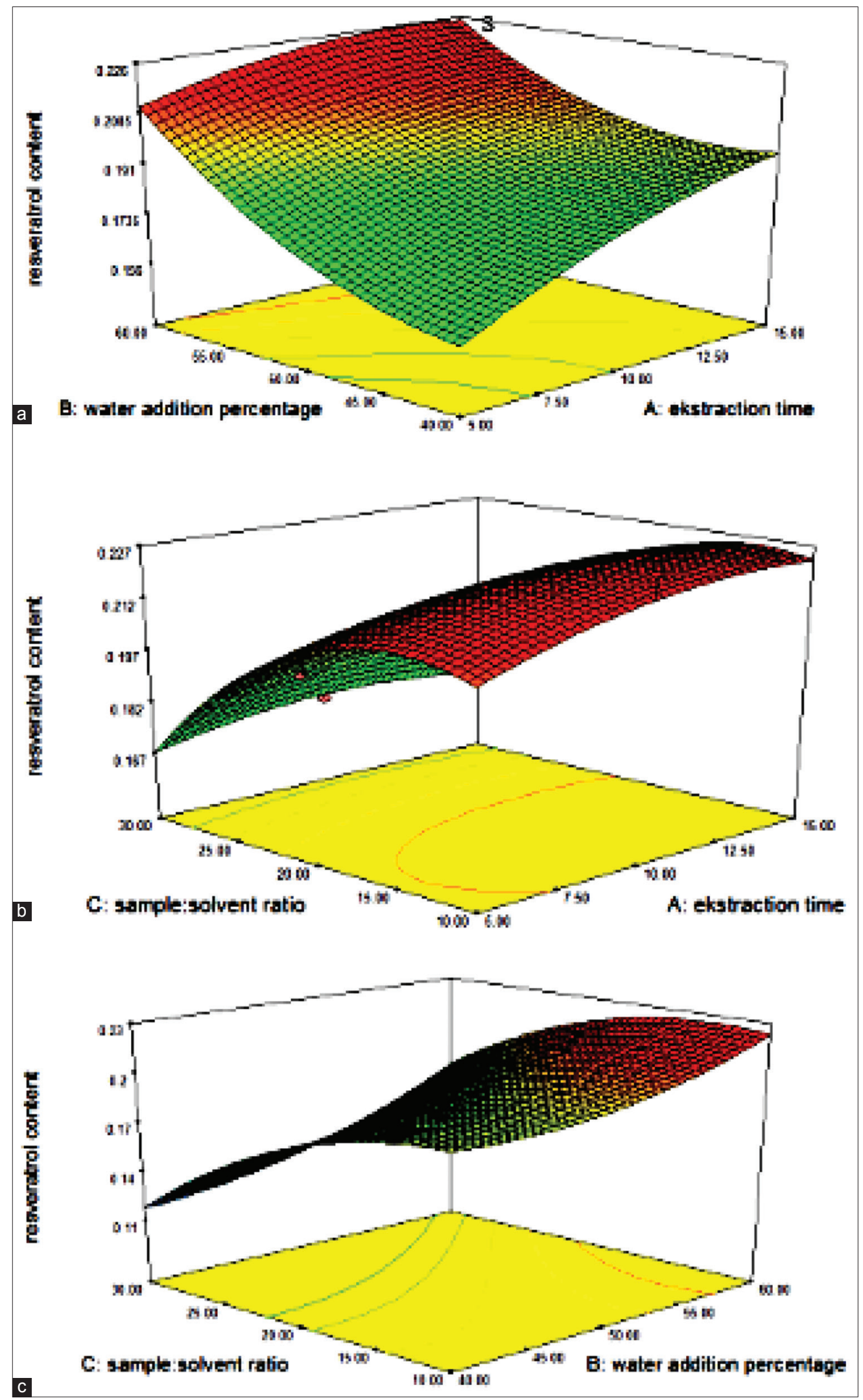

Fig. 5: Three-dimensional response surface graphs evaluating interaction between pairs of factors (a) water percentage: extraction time;

(b) sample: solvent ratio: extraction time; and (c) sample: solvent ratio: water percentage 
Table 3: Optimum extraction conditions

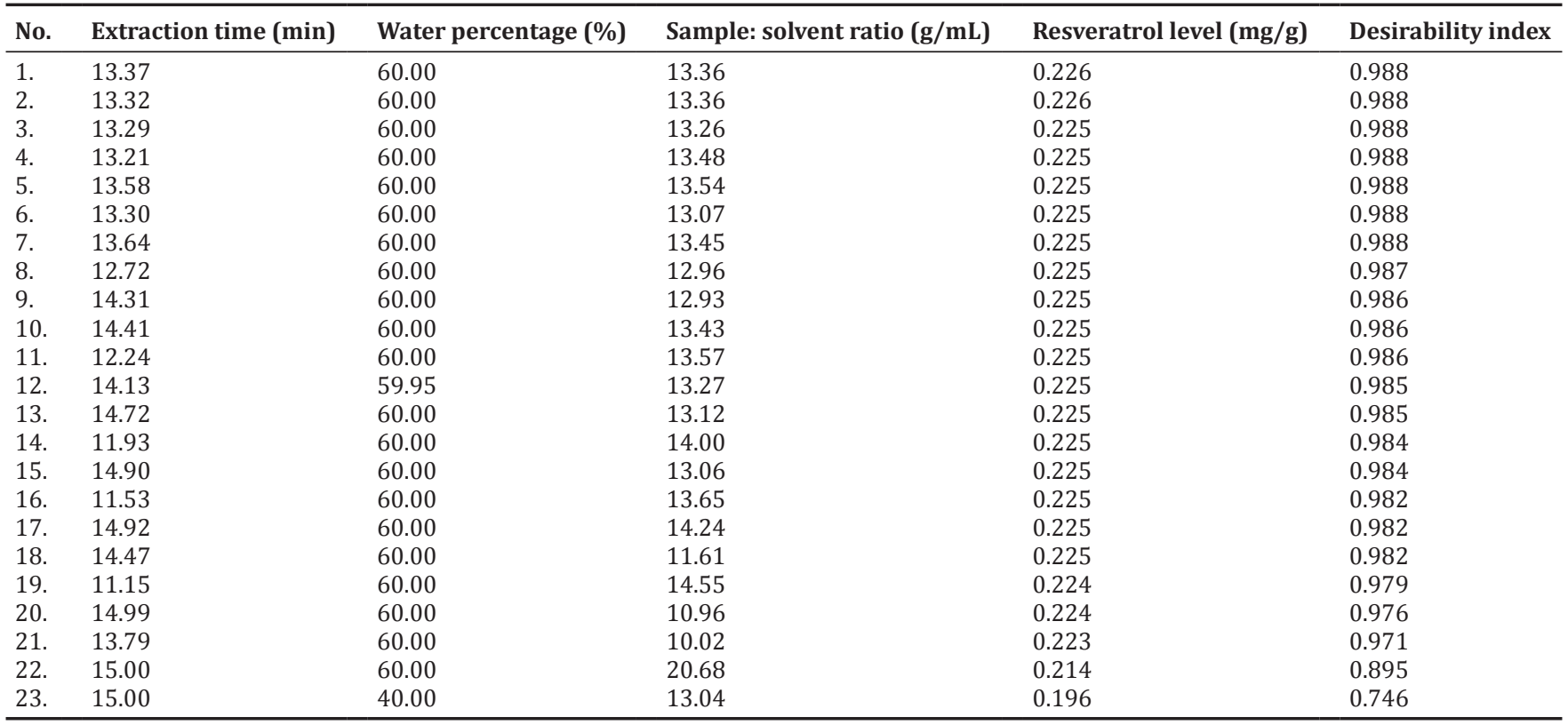

extraction. The extraction in run 6 was also found to be higher than that using ethanol fractionation with the solvent extraction method, which yielded $0.131 \mathrm{mg} / \mathrm{g}$ [18], and higher than the extraction using heat reflux extraction, which yielded $0.093 \mathrm{mg} / \mathrm{g}$ [19]. This indicates that resveratrol extraction using NADES betaine-lactate acid is highly effective.

\section{CONCLUSION}

The most effective betaine-based NADES component was found to be betain-lactic acid, yielding a resveratrol level of $0.334 \mathrm{mg} / \mathrm{g}$ powder. The optimal conditions of resveratrol extraction from irradiated melinjo seeds with optimum UAE were a time of extraction of $10 \mathrm{~min}, 60 \%$ water, and a sample: solvent ratio of 1:10, yielding a resveratrol level of $0.227 \mathrm{mg} / \mathrm{g}$ powder. It can be concluded that betaine-based NADES can be purposed as an alternative solvent for resveratrol extraction from irradiated melinjo seeds.

\section{ACKNOWLEDGMENTS}

The present study was supported by Hibah Tugas Akhir Doktor UI Tahun 2018 from Universitas Indonesia.

\section{CONFLICTS OF INTERESTS}

The author has no conflicts of interest to declare.

\section{REFERENCES}

1. Barua CC, Haloi P, Barua IC. Gnetum gnemon Linn.: A comprehensive review on its biological, pharmacological and pharmacognostical potentials. Int J Pharm Phytochem Res 2015;7:531-9.

International Union for Conservation of Nature. Gnetum gnemon: Baloch E; 2009. Available from:http://www.iucnredlist.org/details/194943/0. [Last accessed on 2019 Sep 09].

2. Manner HI, Buker RS, Smith VE, Ward D, Elevitch C. Gnetum gnemon. Species Profiles for Pacific Island Agroforestry. Hawai' $i$ : Western SARE, Sustainable Agriculture Research and Education; 2006. p. 1-9.

3. Watanabe K, Shibuya S, Ozawa Y, Izuo N, Shimizu T. Resveratrol derivative-rich melinjo seed extract attenuates skin atrophy in sod1deficient mice. Oxid Med Cell Longev 2015;2015:391075.

4. Liu C, Wang L, Wang J, Wu B, Liu W, Fan P, et al. Resveratrols in vitis berry skins and leaves: Their extraction and analysis by HPLC. Food Chem 2013;136:643-9.
5. Chatterjee S, Kumar V, Khole S, Sanyal B, Murali TS, Variyar PS. Radiation processing: An effective quality control tool for hygienization and extending shelf life of a herbal formulation, amritamehari churnam. J Rad Res Appl Sci 2006;9:86-95.

6. Jeong RD, Chu EH, Lee GW, Cho C, Park HJ. Inhibitory effect of gamma irradiation and its application for control of postharvest green mold decay of satsuma mandarins. Int J Food Microbiol 2016;234:1-8.

7. Chemat F, Vian MA, Cravotto G. Green extraction of natural products: Concept and principles. Int J Mol Sci 2012;13:8615-27.

8. Dai Y, van Spronsen J, Witkamp GJ, Verpoorte R, Choi YH. Natural deep eutectic solvents as new potential media for green technology. Anal Chim Acta 2013;766:61-8.

9. Paiva A, Craveiro R, Aroso I, Martins M, Reis RL, Duarte AR. Natural deep eutectic solvents-solvents for the $21^{\text {st }}$ century. ACS Sustain Chem Eng 2014;2:1063-71.

10. Aroso IM, Paiva A, Reis RL, Duarte AR. Natural deep eutectic solvents from choline chloride and betaine-physicochemical properties. J Mol Liq 2017;241:654-61.

11. Duan L, Dou L, Guo L, Li P, Liu E. Comprehensive evaluation of deep eutectic solvents in extraction of bioactive natural products. ACS Sustain Chem Eng 2016;4:2405-11.

12. Fan JP, Yu JX, Xu R, Zheng B, Xu XK, Zhang XH. Optimization of ultrasonic-assisted extraction of three main taxoids in the twigs of Taxus $\times$ media using multi-objective response surface methodology. J Liq Chromatogr Relat Technol 2016;39:394-400.

13. Khodaverdian S, Dabirmanesh B, Heydari A, Dashtban-Moghadam E, Khajeh K, Ghazi F. Activity, stability and structure of laccase in betaine based natural deep eutectic solvents. Int J Biol Macromol 2018;107:2574-9.

14. Bajkacz S, Adamek J. Development of a method based on natural deep eutectic solvents for extraction of flavonoids from food samples. Food Anal Methods 2018;11:1330-44.

15. Espino M, Fernández MD, Gomez FJ, Silva MF. Natural designer solvents for greening analytical chemistry. Trends Analyt Chem 2016;76:126-36.

16. Souto AA, Carneiro MC, Seferin M, Senna MJ, Conz A, Gobbi K. Determination of trans-resveratrol concentrations in Brazilian red wines by HPLC. J Food Compost Anal 2001;14:441-5.

17. Mishima K, Siregar YD, Kawamura H, Kawakami R, Ito S, Inoue Y, et al. Extraction of resveratrol from melinjo (Gnetum gnemon L.) seeds using mixtures of liquid carbon dioxide and ethanol. Solvent Extr Res Dev Jpn 2015;22:69-77.

18. Rachmawati M, Ayuningtyas IN, Sutriyo S, Mun'im A. Comparison of ionic liquid-microwave-assisted extraction and MAE of resveratrol from melinjo (Gnetum gnemon L.) seeds. J Appl Pharm Sci 2017;7:23-9. 